\title{
ENGAGING YOUTH THROUGH SPATIAL SOCIO-TECHNICAL STORYTELLING, PARTICIPATORY GIS, AGENT-BASED MODELING, ONLINE GEOGAMES AND ACTION PROJECTS
}

\author{
Alenka Poplin ${ }^{1}$, Linda Shenk ${ }^{1}$, Caroline Krejci ${ }^{2}$, Ulrike Passe ${ }^{1}$ \\ ${ }^{1}$ Iowa State University, Ames, Iowa, USA (poplin, shenk, passe@iastate.edu) \\ ${ }^{2}$ University of Texas at Arlington (caroline.krejci@uta.edu)
}

KEY WORDS: engaging youth, online serious games, mobile participatory GIS, socio-technical storytelling, action projects

\begin{abstract}
The main goal of this paper is to present the conceptual framework for engaging youth in urban planning activities that simultaneously create locally meaningful positive change. The framework for engaging youth interlinks the use of IT tools such as geographic information systems (GIS), agent-based modelling (ABM), online serious games, and mobile participatory geographic information systems with map-based storytelling and action projects. We summarize the elements of our framework and the first results gained in the program Community Growers established in a neighbourhood community of Des Moines, the capital of Iowa, USA. We conclude the paper with a discussion and future research directions.
\end{abstract}

\section{INTRODUCTION}

Current procedures and activities in urban planning almost completely neglect youth and their involvement in the planning processes and co-creation of our cities and environments. In our research, we contribute to a better understanding of the methods that can be used for empowering youth as community leaders in urban planning and local community action. The main goal of this paper is to present the conceptual framework for engaging youth in planning through an innovative integration of IT tools and methodologies as storytelling mechanisms that support the creation of online geogames and action projects. The framework concentrates on engaging youth from underrepresented populations as co-creators in, and co-designers of, their community. By working with youth on visible community projects, we not only generate "community agency" for the youth but also enhance potential for local change, aiming to make youth community leaders in community capacity building.

We are conducting a community engagement action project involving GIS-based socio-technical storytelling and serious geogames with youth in a resource-vulnerable neighbourhood in the East Bank of Des Moines, Iowa. This project begins with an 8-week program, called Community Growers, that involves a leadership-minded group in the Boys \& Girls Club at the local middle school, using primarily geographic information system (GIS) with some inclusion of agent-based modelling (ABM) both to create and tell the youth's story of the assets of their neighbourhood and then devise an action project the group will plan-in this case, one associated with their school's community garden.

The ideas and maps the youth generate through the program will play a key role when they share their process and action project with neighbourhood residents, the local neighbourhood coalition Viva East Bank!, and City of Des Moines officials at community events. At these events, researchers will collect further data from residents that will, along with the geogames the youth help shape, serve as input for the models and further action for the neighbourhood and city — with the aligned goal to make the East Bank and Des Moines overall a more sustainable, equitable, and connected community.

Our Community Growers program empowers youth as fellow knowledge-producers with both researchers and community leaders. For the research community, this work aims to optimize the narrative capabilities in GIS and ABM to calibrate lived experience with systems-level science, creating a practical strategy for better aligned community-researcher partnerships and outcomes. As a longer term goal, this work, by empowering youth, helps fosters a new generation of community leaders and practitioners who see the utility of GIS and models as interfaces that can join personal experience with systems-thinking, creating a socio-technical culture of action and decision making.

As researchers, we are interested in testing the development and implementation of IT methods and tools that are unique in their combination and have not been often used in civic engagement of youth. The methods we are suggesting are combined in an engagement framework presented in this paper. We will:

- $\quad$ experiment with using GIS, ABM, and online geogames

- $\quad$ observe how the youth utilize these tools

- $\quad$ assess if these tools empower the youth in formulating their visions for their neighbourhood and community

- $\quad$ evaluate how these tools foster the youth's leadership skills as they conduct action projects in the community garden.

The methods we are suggesting are combined in an engagement framework presented in this paper. This paper introduces the conceptual model for engaging youth with a combination of IT tools, presents our engagement approach implemented in Des Moines, Iowa and our initial results. We summarize the main research concepts, outline our future research directions, and conclude the article with a discussion. 


\section{CIVIC ENGAGEMENT IN PLANNING: METHODS AND METHODOLOGIES}

\subsection{Engaging underrepresented youth}

Involving marginalized, underrepresented populations and, additionally, youth in urban planning has long been a challenge, yet these individuals are among the most crucial to engage as cities seek to foster the next generation of decision-makers as well as create more resilient, connected communities. Due to such factors as work-life stresses and language barriers, these populations are the most difficult to engage in feedback and data-collection mechanisms and, therefore, often remain absent from municipal and community decision-making (Maloff 2000). When researchers seek to engage these populations, the typical strategy is to begin with local power-brokers such as landlords, business owners, public officials, developers and other stakeholders. This approach affirms hierarchical relationships that privilege leaders and public officials more than residents.

Conversely, some researchers take a less-travelled path and place youth at the centre of community engagement; however, much work is still done for youth, rather than with youth (Cherry 2011, Derr et al., 2013, International Institute for Child Rights and Development 2015). Youth are rarely included in decision making at either the city or neighbourhood level: "Many youth's voices are absent from community-building processes, deepening the gaps of miscommunication and contributing to community exclusion" (Blanchet-Cohen and Salazar 2009, p. 5-6). Integrating the voices of youth into city and neighbourhood decision-making as well as transdisciplinary scientific research is unusual but also crucial for developing forward-thinking planning and research related to sustainability.

\subsection{Spatial socio-technical storytelling}

As a central component to our methodology, we take as a starting place the notion of storytelling - a longstanding cornerstone of community engagement practices in design, urban planning, and the social sciences. Sharing personal stories and experiences authorizes under-represented populations and non-credentialed stakeholders as fellow knowledge-producers in the creation of new policies and practices (Goldstein et al. 2015). The language of story is also emerging in data science, often as the bridge between data and action (Fuller 2015). Mohanty et al. (2013, p. 255) describe the data scientist as one who brings "scenarios to life by using data and visualization techniques: this is nothing but storytelling." Digital storytelling implements digital media to help create stories, and this focus on the personal works well with youth. The youth initially share their personal experiences but then, using GIS and ABM, begin to "scale up" those stories by using these technologies to help them place their lived experience into larger systems. In particular, using GIS in this capacity is already underway. Recent advancements in GIS-based storytelling focus on the creation of map-based stories, which include multi-media such as a combination of pictures and videos that are geo-located and presented on the map, offered online to everybody with internet access.

In our team, Shenk is developing a methodology-sociotechnical storytelling - that uses the narrative, collaborative, and systems-level capacities of data analytics platforms GIS, VGI and agent-based modelling (ABM) to help communities, and particularly youth, tell larger stories that single-teller, personal reflections of traditional storytelling cannot capture. The focal term of storytelling for this methodology emphasizes the integral role of personal experience and narrative as the foundation, while "socio" introduces the way these elements, through the use of data technologies, get situated within larger systems that have social impact.

For the Community Growers program, working with GIS will help the youth situate their action projects for the garden within issues of food access, personal values, and cultural diversity in their community - issues that expand and deepen the garden as a place solely for food production. Likewise, through use of the $\mathrm{ABM}$, they can explore the social dynamics that lead to powerful community change, giving the youth a space to consider how these dynamics suggest ways of conceiving their work as community leaders. In each case, the data technologies empower new stories that suggest systems-level impacts that personal stories alone may not - at least so swiftly - uncover.

\subsection{Participatory GIS (PPGIS) and Volunteered Geographic Information (VGI)}

Public Participatory GIS (PPGIS) as the research area was established and extensively discussed in the mid-90s (Schroeder 1996). It mostly concentrated on the desktop GIS applications and further development of GIS platforms by adding participatory functions and operations (Kingston et al. 1999, Carver 2001). These applications were first implemented and tested for their technical capabilities and also for their newly included participatory functions (Steinmann, Krek et al. 2004). Later, many researchers stressed the importance of the user interface and usability of PPGIS (Haklay and Tobón 2003, Poplin 2012b, Poplin 2015) for non-GIS experts and technicians.

Development of new technologies and especially mobile devices lead to novel ways of collecting geographic data on a volunteered basis; in such situation citizens may act as sensors (Goodchild 2007a, 2007b, 2007c) contributing data to the GISbased systems that are often freely available online and/or on a variety of mobile devices. Goodchild coined such spatial volunteered applications Volunteered GIS (VGI). In a VGI environment, the user contributes her knowledge about the environment and is able, through a user-friendly user interface, to enter this information/knowledge/data into the system, which stores the data in a geographic database.

\subsection{Research on favourite places and place attachment}

Storytelling is connected to memories, perception, and the way people feel and remember. How do people perceive and experience places in their neighbourhood? Especially how do youth experience these places? What is important to them? Knowing more about the places and perceptions of places may enable urban planners and designers to design more sustainable, pleasant and happy places. Korpela and Hartig studied favourite places (Korpela 1992, Korpela and Hartig 1996, Korpela 2012), which are defined as places that afford restorative experiences and may aid emotional and self-regulation processes. In their initial studies, they worked with young people, especially with adolescents. They asked them to compose an essay describing their favourite places. The adolescence reported about going to their favourite places to relax, calm down, and clear their minds. They also described the experience of beauty, freedom, and escape from social pressures. Their favourite places were described as aesthetically pleasing and engaging. Natural settings such as parks, proximity to water, green areas were overrepresented among favourite places and underrepresented among the unpleasant places. The adolescent participants reported the reduction of anxiety, fears, and social pressures while being at their favourite places. Their research provides 
indications that there is a link between favourite places and restorative experiences.

\subsection{Agent-based modelling research}

Agent-based modelling (ABM) is a type of simulation modelling wherein multiple autonomous agents with intelligence (internal logic) have the ability to make complex decisions and engage in complex interactions with other agents and objects within their environment to achieve one or more identifiable goals. Such interactions may lead to dynamic agent adaptations (i.e., learning) - an agent may collect information about an interaction and then apply this new knowledge to future decisions and behaviours (Gilbert and Troitzsch 2005). The system properties that are introduced through these agent interactions and adaptations over time often result in a system that exhibits behaviour that cannot be predicted by examining the behaviour of its individual parts (Pathak et al. 2007).

One of the most important advantages of $\mathrm{ABM}$ is that it enables humans to be realistically characterized and modelled as boundedly rational agents with complex psychologies that are capable of making subjective choices via explicit decision rules (Bonabeau 2002). Additionally, ABM is a bottom-up modelling approach in which individuals can be represented as discrete heterogeneous agents, which is far more realistic than using a statistical aggregate to model diverse human attributes and behaviours and decentralized decision making (Epstein and Axtell 1996, p. 2). ABM also allows individual agents to learn and adapt their behaviours based on accumulated experiences, which is difficult to do with other modelling approaches. ABM is therefore a particularly appropriate tool for capturing emergent system behaviour as neighbourhood residents interact with each other and their environment.

\subsection{Participatory online serious games}

Recently, games and particularly online serious games have been utilized for engaging stakeholders in participatory activities for urban planning and design. Serious games are games that are designed for more than just entertainment and fun (Ritterfeld et al. 2009). They are sometimes called games for change or learning games. Serious online games may be used in planning and civic engagement for the digital representation of urban plans in a virtual environment merging physical and virtual interaction (Gordon and Manosevitch 2010, Yamu, Poplin et al. 2017) enabling civic engagement and public participation in novel ways (Krek 2008, Poplin 2011, Poplin 2012a, Poplin 2014) in order to be able to overcome what is called rational ignorance of the citizens (Krek 2005). Rational ignorance is a concept according to which the citizens decide that it is not worthwhile to participate in urban planning due to the high cost of acquiring the information and getting informed about the planned activities.

Games (Koster 2004, Salen and Zimmerman 2004) may also be used for collective reflections about the urban planning issues (Devisch et al. 2016) enabling the citizens to express their opinions, co-create and co-design the environments in which they live. They can be designed as geogames, games that intend to represent the environment in a realistic or close to realistic way (Schlieder et al. 2005, Ahlqvist et al. 2012), often based on maps, satellite images or aerial photographs. We hypothesize that games, online games and game-based simulations may provide environments in which players/citizens can be immersed and feel like being in the flow enjoying the engagement and participatory activities.

\section{CONCEPTUAL FRAMEWORK FOR ENGAGING YOUTH INTO CO-CREATION OF THEIR NEIGHBORHOOD}

\subsection{The conceptual framework for engaging youth}

Inspired by these research areas, we envision a combination of these methods in a mix-method engagement framework that aims at finding the combination of these methods that will result in engaged and empowered youth and consequently in better connected communities in the targeted neighbourhoods where underrepresented and marginalized population lives. Figure 1 presents the conceptual framework we envision for engaging youth in the co-creation of their neighbourhood. Our proposed conceptual framework for engaging youth in reflections about their neighbourhood and co-creation of places and spaces includes using modelling tools such as geographic information systems (GIS), agent-based modelling (ABM), story-telling, and mobile volunteered geographic information (VGI).

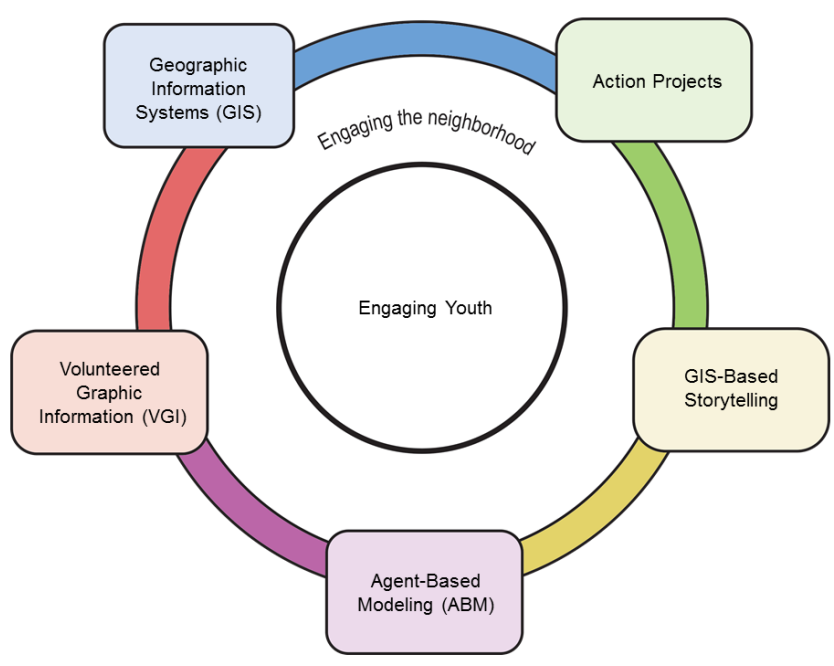

Figure 1. The framework for engaging youth in co-creation of their neighbourhood using modelling tools

The framework integrates data analytics platforms GIS, VGI and agent-based modelling (ABM) directly into communityengaged work through socio-technical storytelling. We adopt an asset-based (strengths-oriented) approach responsive to the community's expressed interests-interests that, significantly, emphasize youth. ABMs are natural tools for socio-technical community engagement: these quantitative computation simulation models show how the individual micro-decisions of agents can lead to macro-level collective action in complex adaptive systems. Research in ABMs is becoming more datadriven and participatory, involving larger ranges of empirical data.

We build on our previous work (Poplin 2012, Passe et al. 2016, Shenk et al. 2016, Shenk, Krejci et al. 2017, Poplin 2017) and include GIS, ABM and online games that are well suited to joining individual, lived experience in a defined spatial area with scalable, systems-level interactions. They are used in a combination for creating and fulfilling action, which at aligned multiple scales has not yet been explored. In our proposed conceptual model for engaging youth create socio-technical stories that help plan and document local, tangible, positive action, placing their work within the widening circles of 
systems-level significance. In turn, such telescoping between the personal and the larger systems helps integrate the views of youth as leaders into the even-larger systems of city and community leaders, thus allowing, we anticipate, the formation of more youth-official-researcher partnerships and collaboration

\subsection{Research focus: A broader research agenda}

Our project includes attention to engaged research as yet another step in mentoring future leaders, citizens, and scientists for community-connected, sustainable cities even as we, as credentialed experts, benefit from the knowledge the youth and their community bring to our work. In our research we concentrate on the following questions:

- Which IT methods and techniques can be optimally used to engage and empower youth?

- In which phases of planning can these methods be used?

- How can these different IT tools be best combined in an engagement process?

- How will the use of geographical information systems (GIS) expand youth understanding of their neighbourhood?

- Is GIS an appropriate, stimulating, intriguing tool for youth engagement?

- How can GIS be best presented, thought and implemented in the phases of youth engagement?

- Can youth feel empowered by using GIS, VGI, ABM, and online geogames?

- How can ABM be presented and utilized to engage youth?

- Will youth feel engaged and empowered by being able to design and use GIS and design their GIS-based stories about their neighbourhood?

We are in the phase of testing the presented conceptual framework for engaging youth into collective reflections and co-creation in the selected neighbourhoods in the capital of Iowa, Des Moines.

\section{METHODS AND TECHNOLOGIES IMPLEMENTED FOR ENGAGING YOUTH INTO CO-CREATION IN DES MOINES, IOWA}

\subsection{Des Moines neighbourhood: Our study area}

Our study area is located in Des Moines, the capital of, and most populous city in Iowa, USA with a population of 203,433 inhabitants as of 2010 census data. Des Moines is a major centre of the U.S. insurance industry and is located along the Des Moines River (Figure 2).

Our test site is located in the city's East Bank neighbourhoods, which were selected as the main focus of our study because they have among the highest levels of under-represented, resourcevulnerable populations in the city. In these neighbourhoods, the median income is about half that of Des Moines overall $(\$ 46,290)$, and all neighbourhoods have a dramatically higher percentage of minority residents, nearly double that of Des Moines overall. The total population of all three neighbourhoods is 8,673 . Over $34 \%$ of the population is under $18.30 \%$ of adults that do not have a high school diploma or other higher educational attainment. Nearly $30 \%$ of the population is living below the poverty line.

Several of these neighbourhoods are mostly Spanish speaking, and the inhabitants experience challenges integrating with
English speaking neighbours. The inhabitants, and especially the youth of these neighbourhoods, are in the centre of our study.

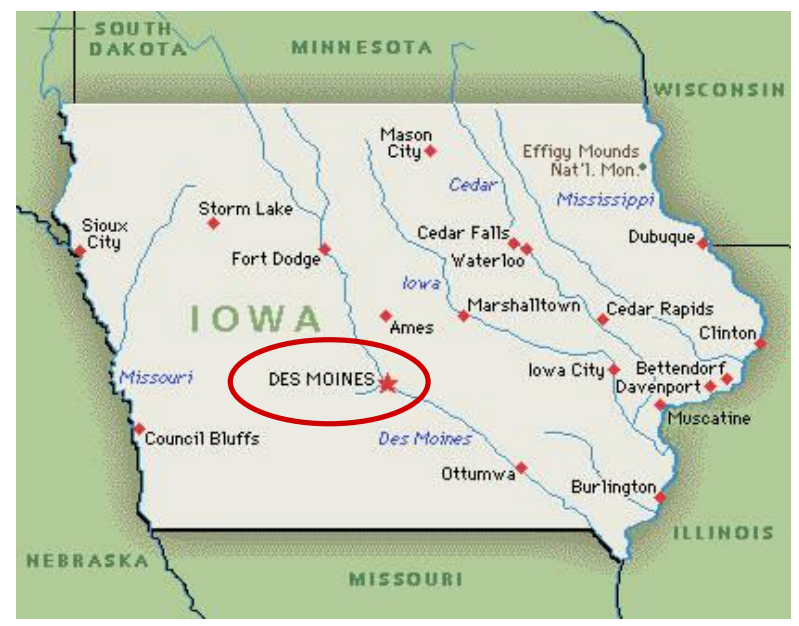

Figure 2. Des Moines, the capital of the state Iowa

Our project partners include the City of Des Moines, the Viva East Bank! coalition, and, most crucially for the Community Growers program, the Baker chapter of the Boys \& Girls Club of Central Iowa which has its facility in the Hiatt Middle School.

\subsection{East Bank neighbourhoods in Des Moines: A common focus on youth}

All three of the East Bank neighbourhoods have high populations of young people, ages 5-17, with percentages averaging $8 \%$ higher than Des Moines overall, and all three neighbourhood plans emphasize the priority of supporting their youth. Our partnership with the Boys \& Girls Club aims to support the community's already-established goal to create opportunities for youth engagement - a situation that both establishes credibility with adult community members and, as Cherry's work (Cherry 2011) on youth and climate change has demonstrated, encourages adults themselves to participate in sustainable practices. In our work, we aim at empowering youth as a crucial entry-point to working with residents in these target neighbourhoods (Shenk et al. 2016).

We begin this work with youth by working with them to create socio-technical stories that help plan and document local, tangible, positive action, placing their work within the layer of systems-level significance of their work. Twenty-two boys and girls signed up to be part of our 8-week program. We meet with them twice a week, on Thursdays and Fridays, for 45-minutes each session, involving them in experimenting with GIS, ABM, story-telling and creation of geogames. An exciting adventure!

\subsection{Community Growers: Spatial storytelling with GIS}

We have called this program "Community Growers" to acknowledge several key aspects: the local community garden connected to the middle school that will form the centre of the action project, the youth's own leadership skills, and the youth's role in nurturing community capacity building. Within this program, the youth will learn about GIS, how to use ArcGIS Online, experiment with map creation and online mapping tools. They will help generate GIS maps that first 
enable visioning work about their favourite places and strengths of the neighbourhood and then begin to integrate how the garden fits into that vision. These explorations will enable them to see their environment from several different perspectives. One of the perspectives is their own, individual perspective (my favourite places) and the other one is the neighbourhood (we, our garden, our community), a more systemic perspective that embeds their personal perspectives into the vision for the community.

The youth will use GIS to discuss what the favourite places mean to them and their community indicating about what their community values, what brings people together, and what the spatial placement of their community garden could suggest about how this space could add to these favourite networks. With these ideas in mind, the youth will explore how they can conduct an action project that tells and adds to the story of what the community garden does, and can, mean to the community. Part of this work with its focus on the Hiatt garden will involve exploring with the youth a more holistic design approach to local food systems and how food systems are related to community values.

Using GIS, they will map how revitalizing the garden connects to neighbourhood systems (community-building, food, health). Using the integrated capacity of GIS to include layers and narrative (through image, text, and video), the youth will generate a story about the garden that situates it within the larger systems of food, community, green spaces, and equityall items that are crucial to decision-makers at the neighbourhood coalition level, the city, and aspects of our larger research team's models.

\subsection{Mapping favourite places with VGI}

The initial activities with the youth include mapping their favourite places, taking pictures of these places, and describing them with words. In the next stage, this data will be inserted into a GIS and into a VGI platform. We plan on using Maptionnaire (maptionnaire.com) for the discussions about their experience of the environment in which they live. Maptionnaire is an online GIS-based participatory platform that enables crowdsourcing, and citizens' engagement into discussions based on map representations of the area subject to the discussions. It also includes analytical capabilities and the ability to store the comments in a common geodatabase. Maptionnaire will be designed, developed and implemented for the needs of this project and especially for the needs of the youth involved into the project. The implementation will first be tested with the ISU students in a pilot study and then used in testing the mobile participation with VGI component in the pilot project with Boys \& Girls Club in Des Moines. The advantage of Maptionnaire is that it stores the entered data in a geographical database. This data can be then further used for a variety of spatial analysis, spatial queries and statistics.

\subsection{Community Growers, Growing Community: ABM}

We will introduce a prototype agent-based model (ABM) that shows how community connectedness, collaboration, and knowledge sharing can magnify the impact of individual residents' decisions to improve a community's overall quality of life. Introducing youth to the concept of ABM and a developed $\mathrm{ABM}$ prototype aims to support the powerful significance of the youth's work to generate projects that create and foster community.
The prototype $\mathrm{ABM}$ is a neighbourhood-level model that conveys possibilities for individual decisions and interactions to improve community sustainability (Figure 3 ).

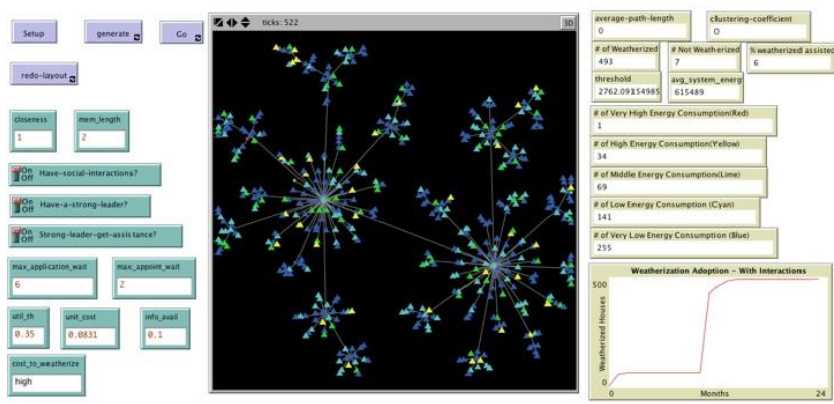

Figure 3. ABM created for weatherization related to sustainable cities

This model will suggest smaller, actionable stories that align with the strategies that decision-leaders and researchers are addressing at the larger scales. Figure 5 shows the user interface of the ABM, which integrates social network analysis to determine the effects of residents' social connections on neighbourhood-level behaviour. These ABM-based discussions may encourage the youth to include and plan a community event at the garden where they can not only share their storymaps and action project but situate that work within an event that naturally encourages further community capacity building. Through an introduction to $\mathrm{ABM}$, they will be empowered to shape and determine an action project that they will work on over the summer.

\subsection{Participatory design: online serious game $e$-footprints}

The game e-footprints was designed in an interactive process over several months by our research team. It concentrates on energy use and consumption with the focus on built environment and has three main goals. First, it aims to engage citizens/inhabitants in online discussions and reflections about their homes and in particular about the consumption of energy in their homes. Second, it enables data collection about human behaviour in relation to the consumption and saving of energy. Third, it is designed as a teaching and learning tool that aims to provide new insights into the possibilities for energy saving and other activities related to the maintenance of the home and its improved energy efficiency.

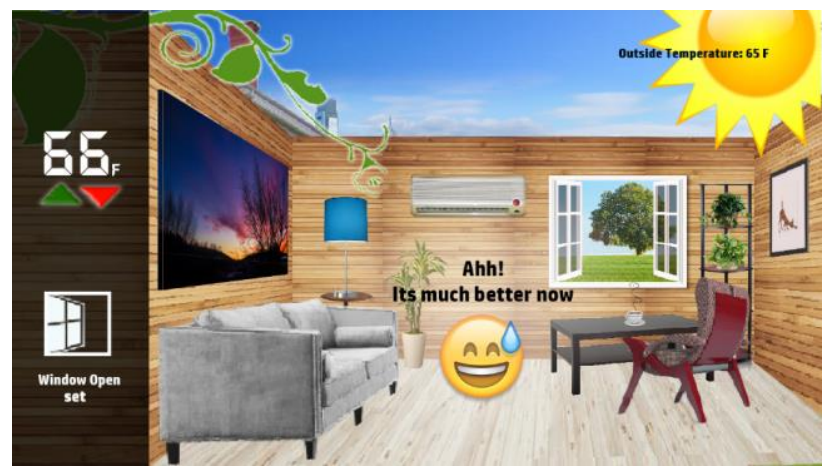

Figure 4 . The room of the online serious game $e$-footprints

The online energy game e-footprints takes the player into a room of the previously selected house (Figure 4); the room is interactive and enables the players to set up the temperature 
inside displaying the temperature outside, open/close the window, and turn on/off the air conditioner. In order to increase the playfulness and the "conflict" in the game, random events and wisdom puzzles are introduced on the next level of the game.

Random events appear suddenly as a surprise and may include extreme heat/extreme cold events or the energy bill might go up. Wisdom puzzles are included as learning tools and enable additional simulations, provide links to the learning material, and mostly concentrate on learning about activities related to the energy of a home, and the effects of activities and human decision-making on energy consumption and saving. Currently we are in the phase of testing the developed e-footprints game prototype in order to be able to improve the user interface, graphical visualization, and aesthetics of the game prototype.

\subsection{Community garden: the action project}

Over the summer and early fall, members of our research team will conduct the action project and a community festival with the Community Growers group. This work is based on our previous involvement with the community garden. The youth will play key roles in transforming the garden into a more welcoming space that emphasizes unity and partnership.

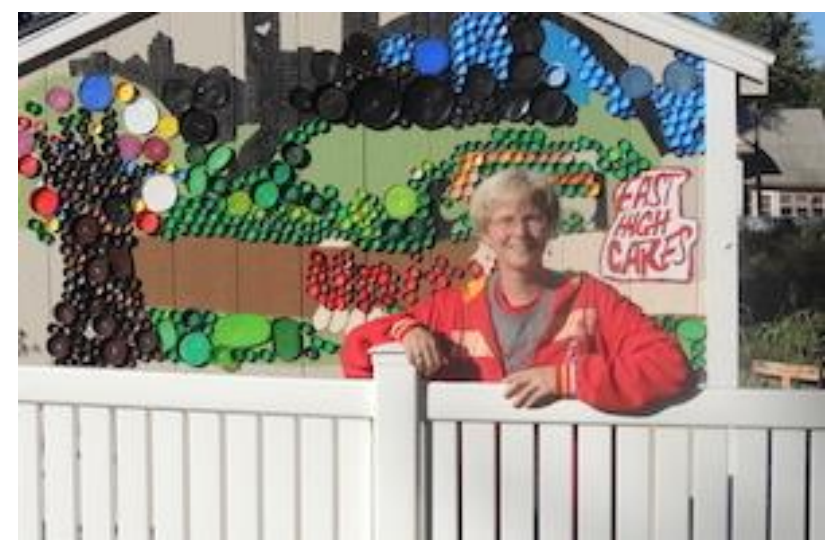

Figure 5. Community garden project and its leader Linda Shenk

Figure 5 shows the end result as a colourful artwork. In the continuation of this project, we intend to connect the activities on the garden with storytelling, and using GIS, ABM and online games to place the garden into a broader perspective. The broader perspective encompasses looking at the garden as part of the food system of the neighbourhood, but also as a meeting place, perhaps even power places or a favourite place for some of the students. It may also be seen and perceived as the place that can connect the youth of the neighbourhood with their parents, mentors, teachers, and city leaders.

\section{FUTURE RESEARCH}

Our presented framework for engaging the youth in an underrepresented neighbourhood is currently in the testing phase. We have started the 8-week program with the Boys \& Girls Club in which we will test the framework for engaging youth in reflections about their neighbourhood. Our future research involves additional steps in the integration of the following models.
Online geogame $e$-footprints and urban modelling interface (umi). The e-footprints game-based simulation aims to integrate the simulations and results gained from the urban modelling interface (umi), which is a modelling platform to design and improve new and existing neighbourhoods via measures of energy use, daylighting, outdoor comfort, and sustainable transportation (Reinhart and Cerezo Davila 2016, Carezo Devila et al. 2017).

\section{umi and GIS}

The integration of umi and GIS will enable umi model to extract geometric and building property information from the city's GIS model and store various performance indicators, such as operational and embodied energy, indoor and outdoor access to daylight and neighbourhood walkability.

\section{$\mathrm{ABM}$ and GIS}

We will be working on an integration of GIS and ABM; they both have their strengths. ABM is able to model dynamic, changing objects modelled as agents. GIS on the contrary can very well represent geography and space and can be very exact in doing so. We will explore how these two models can be integrated in modelling residents' energy consumption, saving, and decision-making.

\section{$\mathrm{ABM}$ and $e$-footprints online game}

Based on the patterns of the behaviour in the game will be explored for the possibility to create personas, agents with their specific patterns of behaviour. These personas will serve as an input information in defining the behaviour and decisionmaking of the agents modelled in the agent-based model.

\section{CONCLUSIONS}

In this paper we summarize the conceptual framework for youth engagement into urban planning, especially into the process of co-creation and co-design of their neighbourhood and spatial reflections about the places in their neighbourhood. The presented framework concentrates on the utilization of IT tools such as geographic information systems (GIS), volunteered geographic information systems (VGI), and agent-based modelling $(\mathrm{ABM})$ in the process of engaging youth into reflections about their living environment. This framework is in the testing phase in the selected neighbourhoods in Des Moines, the capital of Iowa.

By bringing together the narrative capabilities of data science through GIS and some ABM with community engagement with youth, we aim to empower youth to connect personal experience with systems-thinking, creating a youth-generated sociotechnical culture of action and decision-making that can move from personal to neighbourhood to city scales. The initial steps for devising the action project will focus on the garden within community systems, and, as those plans are forming, these plans will expand to include other aspects of sustainability. Our work demonstrates how GIS and ABM, together, can help generate community stories in which residents and communities can "scale up" their lived experience to have impact on larger systems. GIS will support spatial representations, visualizations and map-based discussions. VGI will enable exploring and mapping favourite places. The ABM we will use will help reveal and test how their work in community building and knowledge sharing supports and extends the impact of the action projects the youth create and share. The main goal of our research is to observe how youth use these IT tools, what are the possibilities for their implementation in the phases of spatial reflections and co-creation, and whether these tools can 
empower the youth with skills needed for them to become future community leaders, citizens, scholars, and scientists poised to better our communities.

\section{ACKNOWLEDGEMENTS}

This research has been funded through Iowa State's Presidential Initiative for Interdisciplinary Research in Data-Driven Science for the project: "Big Data for Sustainable Cities DecisionMaking." Special thanks to our ISU Extension colleague Caitlin Szymanski, to Industrial Engineering student Kate Fjelstad, and to the Community and Regional Planning students (CRP) at ISU, Braden Cervetti, Kara Harmet, and Carlee Tope for their support in this project and their enthusiasm in creating the needed materials, including activities, maps, and GIS visualizations.

\section{REFERENCES}

Ahlqvist, O., Loffing, T., Ramanathan, J. and A. Kocher (2012). Geospatial human-environment simulation through integration of Massive Multiplayer Online Games and Geographic Information Systems. Transactions in GIS 16(3): 331-350.

Blanchet-Cohen, N. and J. Salazar (2009). Empowering practices for working with marginalized youth. Relational Child and Youth Care Practice, 22 (4), 5-15.

Bonabeau, E. (2002). Agent-based modeling: Methods and techniques for simulating human systems. In Proceedings of the National Academy of Sciences 99(3): 7280-7287.

Carver, S. (2001). Participation and Geographical Information. position paper, ESF-NSF Workshop. Spoleto, Italy.

Cerezo Davila, C., Sokol, J., AlKhaled, S., Al-Mumin, A., Hajiah, A. and C. Reinhart (2017). Implementation of a calibrated Urban Building Energy Model (UBEM) for the evaluation of energy efficiency scenarios in a Kuwaiti residential neighborhood. Building Simulation 2017. San Francisco, USA.

Cherry, L. (2011). Young voices on climate change: The Paul F-Brandwein 2010 NSTA Lecture. Journal of Science Education \& Technology, 20: 208-213.

Derr, V., Chawla, L., Mintzer, M., Flanders Cushing, D. and W. van Vliet (2013). A city for all citizens: Integrating children and youth from marginalized populations into city planning. Buildings, 3(3), 482-505.

Devisch, O., Poplin, A. and S. Sofronie (2016). The Gamification of Civic Participation. Two experiments in improving the skills of citizens to reflect collectively on spatial issues. Journal of Urban Technology 23(2): 81-102.

Epstein, J. M. and Axtell, R. (1996). Growing Artificial Societies: Social Science from the Bottom Up. Brookings Institution Press \& MIT Press: Cambridge, MA.

Fuller, M. (2015). Big data: New science, new challenges, new dialogical opportunities. Zygon 50(3): 569-582.

Gilbert, N. and K. G. Troitzsch (2005). Simulation for the Social Scientist, 2nd edition, Open University Press, McGrawHill, United Kingdom.
Goldstein, B. E., Wessells, A.T., Lejano, R. and W. Butler (2015). Narrating resilience: Transforming urban systems through collaborative storytelling. Urban Studies 52(7): 12851303.

Goodchild, M. F. (2007a). Citizens as sensors: Web 2.0 and the volunteering of geographic information. Geofocus 7: 8-10.

Goodchild, M. F. (2007b). Citizens as voluntary sensors: spatial data infrastructure in the world of Web 2.0. International Journal of Spatial Data Infrastructures Research 2: 24-32.

Goodchild, M. F. (2007c). Citizens as sensors: The world of volunteered geography. GeoJournal 69(4): 211-221.

Gordon, E. and E. Manosevitch (2010). Augmented Deliberation: Merging Physical and Virtual Interaction to Engage Communities in Urban Planning. New Media and Society 13(1): 75-95.

Haklay, M. (2010). How good is volunteered geographical information? A comparative study of OpenStreetMap and Ordnance Survey datasets. Environment and Planning B 37(4): $682-703$.

Haklay, M. and C. Tobón (2003). Usability Engineering and PP GIS: towards a Learning-improving Cycle. International Journal of Geographical Information Science (IJGIS), 17(6): 577-592.

International Institute for Child Rights and Development. (2015). YouthScape. Retrieved May 25, 2016, from http://www.iicrd.org/projects/youthscape.

Kingston, R., Carver, S., Evans, A. and I. Turton (1999). Virtual Decision Making in Spatial Planning: Web-based Geographical Information Systems for Public Participation in Environmental Decision Making. Retrieved August 20, 2017 from http://www.geog.leeds.ac.uk/papers/99-9/.

Korpela, K. (1992). Adolescents' favourite places and environmental self-regulation. Journal of Environmental Psychology 12: 249-258.

Korpela, K. (2012). Place attachment. The Oxford Handbook of Environmental and Conservation Psychology. S. Clayton. New York, Oxford University Press: 148-163.

Korpela, K. and T. Hartig (1996). Resotrative Qualities of Places. Journal of Environmental Psychology 16: 221-233.

Koster, R. (2004). A theory of fun for game design Scottsdale, Arizona, USA, Paraglyph Press.

Krejci, C. C., Stone, R. T., Dornreich, M. C. and S. B. Gilbert (2016). Analysis of food hub commerce and participation using agent-based modeling: Integrating financial and social drivers. Human Factors 58(1): 58-79.

Krek, A. (2005). Rational Ignorance of the Citizens in Public Participatory Planning. International Conference on Urban Planning, Regional Development and Information Society CORP 2005, Vienna, Austria. 
Krek, A. (2008). Games in Urban Planning: The Power of Playful Public Participation. Mobility Nodes as Innovation Hubs. Proceedings of 13th International Conference on Urban Planning, Regional Development and Information Society. u. a. Manfred Schenk. Schwechat-Rannersdorf: pp. S. 683-669. ISBN: 978-39502139-39502135-39502139.

Mohanty, S., Jagadeesh, M., \& Srivatsa, H. (2013). Big Data imperatives: Enterprise 'Big Data' warehouse, BI implementations and analytics. Berkeley, CA: Apress.

Passe, U., Anderson, N., De Brabanter, K., Dorneich, M.C., Krejci, C.C., Poplin, A., Shenk, L. (2016). Methodologies for Studying Human-Microclimate Interactions for Resilient, Smart City Decision-Making. PLEA2016 Los Angeles - Cities, Buildings, People: Towards Regenerative Environments. Los Angeles, USA.

Pathak, S. D., Day, J.M., Nair, A., Sawaya, W.J. and M.M. Kristal (2007). Complexity and adaptivity in supply networks: Building supply network theory using a complex adaptive systems perspective. Decision Sciences 38(4): 547-580.

Poplin, A. (2011). Games and Serious Games in Urban Planning: Study Cases. Lecture Notes in Computer Science (LNCS). Santander, Spain, Springer LNCS. ICCSA 2011 Proceedings.

Poplin, A. (2012a). Playful public participation in urban planning: A case study for online serious games. Computers, Environment and Urban Systems, Elsevier 36(3): 195-206.

Poplin, A. (2012b). Web-based PPGIS for Wilhelmsburg, Germany: an Integration of Interactive GIS-based Maps with an Online Questionnaire. Special Issue of the Journal of Urban and Regional Information Systems Association (URISA), 25(2): 71-84.

Poplin, A. (2014). Digital serious game for urban planning: B3 - Design your Marketplace! Environment and Planning B: Planning and Design 41(3): 493-511.

Poplin, A. (2015). How User-Friendly are Online Interactive Maps? Survey Based on Experiments with Heterogeneous Users. Cartography and Geographic Information Science 42(4): 358-376.

Poplin, A. (2017). Mapping Expressed Emotions: Empirical Experiments on Power Places: Experiments with Maps. Special issue of the journal Kartographische Nachrichten on Empirical Cartography, 2, 83-91.

Reinhart, C. and C. Cerezo Davila (2016). Urban building energy modeling: A review of a nascent field. Building and Environment 97: 196-202.

Reinhart, C., Jakubiec J.A., Dogan, T. and A. Sang (2013). Umi-an urban simulation environment for building energy use, daylighting and walkability. 13th Conference of International Building Performance Simulation Association.

Ritterfeld, U., Cody, M. J. and P. Vorderer (2009). Serious Games: Mechanisms and Effects. New York and London, Routledge.
Salen, K. and E. Zimmerman (2004). Rules of Play, Game Design Fundamentals. Cambridge, Massachusetts, The MIT Press.

Schlieder, C., Kiefer, P. and S. Matyas (2005). Geogames: A Conceptual Framework and Tool for the Design of LocationBased Games from Classic Board Games. Proc. of the First International Conference on Intelligent Technologies for Interactive Entertainment (INTETAIN). M. e. a. Maybury. Madonna di Campiglio, Italy, Springer: Berlin Heidelberg: 164173.

Schroeder, P. (1996). Report on Public Participation GIS Workshop, NCGIA Technical Report 96-97, Scientific Report for Initiative 19 Specialist Meeting.

Shenk, L., Anderson, N. and U. Passe (2016). Engaged science and working with youth for sustainable cities: A partnership between "East High Cares" and an Iowa State University research team. Confronting the Challenges of Public Participation: Issues in Environmental, Planning and Health Decision-Making, Ames, Iowa, USA, Charleston, SC: CreateSpace.

Shenk, L., Krejci, C., M. Dorneich, U. Passe, W. Huang and J. Stonewall (2017). When the humanities partner with engineering and design for community capacity-building: Codesigning a community's story of weatherization using agentbased modeling. Community Development Society Conference, Big Sky, Montana.

Steinmann, R., Krek, A. and T. Blaschke (2004). Can Online Map-Based Applications Improve Citizen Participation? . Lecture Notes in Computer Science, TED on e-government 2004. Bozen, Italy, Springer Verlag.

Surana, A., Kumara, S., Greaves, M. and U.N. Raghavan (2005). Supply-chain networks: a complex adaptive systems perspective. International Journal of Production Research 40(20): 4235-4265.

Yamu, C., Poplin, A., Devisch, O. and G. de Roo (2017). The Virtual and the Real in Planning and Urban Design: Perspectives, Practices and Applications. UK, Routledge. 